Bangl. J. Vet. Med. (2011). 9(1): 85 - 93

\title{
ISOLATION, IDENTIFICATION AND CHARACTERIZATION OF SALMONELLA SEROVARS FROM DIARRHOEIC STOOL SAMPLES OF HUMAN
}

\author{
M. K Nesa ${ }^{1}$, M. S. R. Khan ${ }^{1}$ and M. Alam ${ }^{2}$ \\ ${ }^{1}$ Department of Microbiology and Hygiene, Bangladesh Agricultural University, Mymensingh \\ ${ }^{2}$ International Centre for Diarrhoeal Disease Research, Bangladesh, Dhaka
}

\begin{abstract}
The present study aimed at isolation and identification of Salmonella serovars from human stool and characterization of the isolated serovars using biochemical, serological, molecular and antimicrobial sensitivity techniques. A total of 25 samples were collected of which $16 \%$ were positive to Salmonella serovars. All the culturally positive isolates fermented dextrose, maltose and mannitol with the peoduction of acid and gas but not fermented sucrose and lactose. The same isolates showed Indole and V-P tests negative but M-R test positive. All the culturally and biochemically positive Salmonella serovars showed agglutination with poly 'O' and poly ' $\mathrm{H}$ ' antisera. The antimicrobial susceptibility testing showed that the isolated Salmonella serovars were highly sensitive to ciprofloxacin and moderately sensitive to chloramphenicol, kanamycin, cotrimoxazol and nalidixic acid. However, the positive isolates were resistant to erythromycin. The present study indicates that ciprofloxacin can be used as a first line therapy for the treatment of Salmonella gastroenteritis.
\end{abstract}

Keywords: Isolation, characterization, sensitivity, Salmonella, human stool

\section{INTRODUCTION}

Salmonellosis is a disease condition caused by a large group of bacteria of the genus Salmonella that can affect human being throughout the world. Salmonella infection remains as a serious problem to public health significance in world wide (Tubaraiae et al., 1994) and causes substantial economic loss resulting from mortality, morbidity and poor growth with hazard of transmitting food poisoning with gastroenteritis to human and represents a serious problem for the food industry (Khan et al., 2007). Human spreads Salmonella mainly through the stool. Food borne illness among the people and transmission can occur when food and water are contaminated with stool or through direct fecal-oral route. Human stool acts as an important reservoir of Salmonella serovars that are the grouping of micro organisms based on their cell surface antigen. Species isolated from human stool are Salmonella typhi, S. paratyphi A, S. typhimurium, S. wrothington and S. enteritidis (Kumar et al., 2009). Salmonella is a world wide issue in public health sector. People most at risk for serious complications due to Salmonella food poisoning include older adults, pregnant women, infants, children, and people who have compromised immune systems. Salmonellosis is manifested clinically in all hosts by one of three major syndromes, per acute systemic infection, an acute enteritis or a chronic enteritis (Merchant and Packer, 1967). Symptoms are usually including headache, nausea, vomiting, fatigue, gastroenteritis, abdominal cramps and bloody diarrhea with mucus and sometimes reactive arthritis (Reiters syndrome) (Dworkin et al., 2001). Following Salmonellosis dehydration with renal insufficiency and death may occur.

The importance of Salmonellosis in public health sector is a growing concern day by day throughout the world and over the last several decades there have been significant shift in predominant Salmonella serovars associated with human infections (Steven et al., 2011). Salmonellosis in the past has caused tremendous loss to society in many countries around the world. Two to four million of cases have been reported annually and yet a significant number of cases have been unreported worldwide. Non-typhoidal Salmonella is the leading cause of food borne illness and its increasing antimicrobial resistance is associated with higher risks of hospitalization in Bangladesh (ICDDR,B) (Salam et al., 2003). Non-typhi Salmonella was found responsible for $66 \%$ cases of food borne illness in Bangladesh. The highest proportion (15\%) was isolated in 1998 followed by in $1995(13 \%)$ while it was less than $10 \%$ for other years. Thirty six percent were isolated during the summer while $28 \%$ were in the fall. There is lack of sufficient studies emphasizing isolation and characterization of Salmonella serovars considering human stool in Bangladesh. Moreover, knowledge of manifestation of pathogenicity as well as 
antigenic mosaic of these species would certainly help in suggesting prophylactive measures there of. This, in turn, will go a long way to avoid much of our loss and inconvenience concerned in public health. In view of these considerations, the present study was undertaken with the following objectives of (i) to isolate and identify Salmonella serovars from human stool, (ii) to characterize the isolated Salmonella serovars using cultural, biochemical and serological techniques and (iii) to study the antibacterial sensitivity of the isolated Salmonella serovars.

\section{MATERIALS AND METHODS}

The present research was conducted during the period of June 2009 to May 2010 in the Bacteriology Laboratory of the Department of Microbiology and Hygiene, BAU, Mymensingh. A total of 25 diarrhoeic stool samples were collected for the study. Among the samples 9 were from BAU Diabetic Center (BDC) and the rest 16 were from Mymensingh Medical College Hospital (MMCH). The entire study was divided into two major steps. The first step included selection of sources, collection of samples, transportation to the laboratory, isolation and identification of Salmonellae on the basis of their colony morphology, staining property, motility and biochemical and serological characteristics. In the second step, the current statuses of drugs sensitivity and resistance patterns of isolated bacteria were determined. After collection, each sample was inoculated into freshly prepared Nutrient broth (NB), identified into tube properly and incubated at $37^{\circ} \mathrm{C}$ for 24 hours aerobically in bacteriological incubator. Then, a loop full of bacterial culture from incubated tubes were streaked separately into the Salmonella-Shigella agar (SSA), McConkey agar (MCA), Eosin methylene blue agar (EMBA) and Brilliant green agar (BGA) plates. The plates were examined and studied carefully for the presence of characteristic colonies of Salmonellae. Nailidixic acid (NA) medium was used to grow the organisms from the collected samples. The representative Salmonella colonies were characterized morphologically using Gram's staining method according to the method described by Merchant and Packer (1967). For carbohydrate fermentation tests, triple sugar iron agar (TSIA) slant reaction, methyl red-Voges-Proskauer (MR-VP) and Indole reaction tests were carried out for identification of suspected Salmonella according to the methods described by Douglas et al. (1998) and OIE (2000). The carbohydrate fermentation test was performed by inoculating a loop full of NB culture of the organisms into the tubes containing different sugar media. Acid production was indicated by the color change reddish to yellow in the medium and the gas production was noted by the appearance of gas bubbles in the inverted Durham's tube. The TSIA slant was used to detect the lactose fermenters and the saccharose and dextrose fermenters. The medium also helped to determine the ability of the organisms to produce $\mathrm{H}_{2} \mathrm{~S}$. Pinkish slant and yellow butt or black slant and yellow butt were recorded as the positive reaction for Salmonella.

The MR test was conducted by inoculating a colony of the test organism in $0.5 \mathrm{ml}$ sterile glucose phosphate broth. A red coloration was positive and indicated an acid $\mathrm{pH}$ of 4.5 or less resulting from the fermentation of glucose. A yellow coloration was considered as negative. In VP test, 2 milliliter of sterile glucose phosphate peptone water was inoculated with the $5 \mathrm{ml}$ of test culture. It was observed closely for the slow development of a pink color for positive cases. Two milliliters of peptone water was inoculated with $5 \mathrm{ml}$ of bacterial culture and incubated for 48 hours to conduct Indole test. Kovac's reagent $(0.5 \mathrm{ml})$ was also added. A red color in the reagent layer indicated indole (Cheesbrough, 1985). The motility test was performed according to the method described by Cowan (1985) to differentiate motile bacteria from the non-motile one. The motile and non-motile organisms were identified by observing motility in contrasting with Brownian movement of bacteria. Salmonella agglutinating antiserum poly ' $\mathrm{O}$ ' and poly ' $\mathrm{H}$ ' of S \& E reagents Lab, Bangkok, Thailand was used to do the serotyping of the isolated Salmonella. According to manufacturer's direction, it was noted that poly 'O' antiserum gives positive agglutination reaction with any serovars for preliminary screening of Salmonella and poly 'H' antiserum gives specific agglutination reaction for motile Salmonella (Santiviago et al., 2001). The organisms isolated and identified as Salmonella were inoculated into the SSA slants and incubated at $37^{\circ} \mathrm{C}$ for 24 hours in bacteriological incubatory. Then a loop full of thick bacterial culture was mixed with $20 \%$ sterile buffered glycerin in small vials and was preserved at $20^{\circ} \mathrm{C}$. This method is more appropriate for preserving bacteria with no deviation of their original characters for several years (Buxton and Fraser, 1977). Susceptibility of the isolated Salmonella to different antibacterial agents as performed through disc diffusion method to determine the drug sensitivity pattern according to the method described by Bauser et al., (1966). This method allows the rapid determination of the efficacy of a drug by measuring the diameter of the zone of inhibition that result from different rates of diffusion of the agent into the medium surrounding the disc. 
Isolation, identification and characterization of salmonella serovars

\section{RESULTS AND DISCUSSION}

Salmonella was detected in $16 \%$ of the collected samples under study (Table 1). NB inoculated separately with the collected samples revealed the growth of bacteria after 24 hours of incubation at $37^{\circ} \mathrm{C}$ aerobically and was indicated by the presence of turbidity. In the same way, the growth was indicated by the growth of circular, smooth, opaque, translucent colonies in nutrient agar plates streaked separately. On SSA plates, the organisms were produced pinhead or lentil sized, raised, round or circular smooth, glistening, opaque, colorless, transparent or translucent colonies and on BGA plates, they were produced pale pink color colonies against a pinkish background. In the case of MCA plates, the organisms were produced colorless, smooth colonies while they were produced black color colonies on TSIA slant. The thin smears prepared with the colony from SSA, MCA and BGA for Gram's staining revealed Gram-negative, pink colored, small rod shaped appearance, arranged in single or paired under the microscopic examination (Fig. 1). All the isolates were found to be motile having swinging movement when examined using hanging drop slide under microscope (Table 1).

Table 1. Detection of Salmonella serovars based on cultural, staining and morphological characters

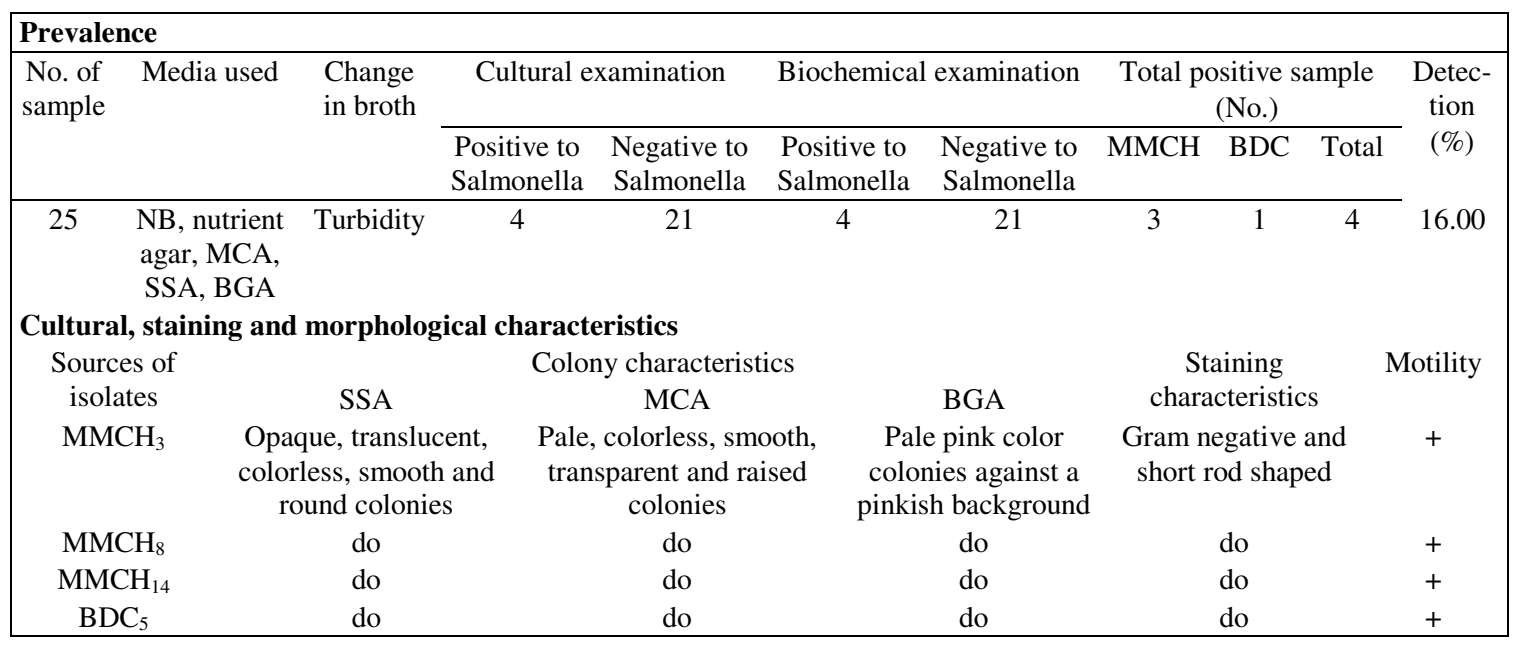

All of the isolates fermented dextrose, maltose and mannitol with the production of acid and gas but did not ferment lactose and sucrose. Acid production was indicated by the color change from reddish to yellow and gas production was noted by the presence of gas bubbles in the inverted Durham's tubes (Fig. 2). All of the isolates were found to be indole negative, MR test positive and VP test negative (Fig. 3, Table 2). The rapid slide agglutination test with polyvalent ' $\mathrm{O}$ ' (Poly 'O') and Polyvalent ' $\mathrm{H}$ ' (poly ' $\mathrm{H}$ ') antisera was conducted with all the isolated Salmonella serovars. In this test, all culturally and biochemically positive Salmonella serovars showed agglutination with poly ' $\mathrm{O}$ ' and in case of polyvalent poly ' $\mathrm{H}$ ', all isolates gave positive reaction (Fig. 4). In-vitro antibiotic sensitivity pattern of isolated Salmonellae was performed against 8 commonly used antibiotics belonging to different groups. After incubation, plates were examined and diameters of the zone of inhibition for individual antibacterial agents were designated as highly sensitive, moderately sensitive, less sensitive and resistant (Table 2). 
Table 2. Characteristics of Salmonella serovars in biochemical and antibiotic sensitivity tests

\begin{tabular}{|c|c|c|c|c|c|c|c|c|}
\hline \multicolumn{9}{|c|}{ Biochemical test } \\
\hline \multirow{2}{*}{ Isolates } & \multicolumn{5}{|c|}{ Carbohydrate fermentation test } & \multirow[t]{2}{*}{ Indole } & \multirow[t]{2}{*}{ MR } & \multirow[t]{2}{*}{$\mathrm{V}-\mathrm{P}$} \\
\hline & Dextrose & Maltose & Lactose & Sucrose & Mannitol & & & \\
\hline $\mathrm{MMCH}_{3}$ & + & + & - & - & + & - & + & - \\
\hline $\mathrm{MMCH}_{8}$ & + & + & - & - & + & - & + & - \\
\hline $\mathrm{MMCH}_{14}$ & + & + & - & - & + & - & + & - \\
\hline $\mathrm{BDC}_{5}$ & + & + & - & - & + & - & + & - \\
\hline \multicolumn{9}{|c|}{ Antibiotic sensitivity test } \\
\hline \multirow[t]{2}{*}{ Isolates } & \multicolumn{8}{|c|}{ Antibiotic disc used } \\
\hline & ER & $\mathrm{AX}$ & $\mathrm{CP}$ & CK & $\mathrm{CT}$ & KA & CI & NA \\
\hline $\mathrm{MMCH}_{3}$ & + & + & + & + & ++ & ++ & +++ & ++ \\
\hline $\mathrm{MMCH}_{8}$ & - & + & + & ++ & + & ++ & +++ & ++ \\
\hline $\mathrm{MMCH}_{14}$ & - & + & ++ & ++ & + & +++ & +++ & ++ \\
\hline $\mathrm{BDC}_{5}$ & + & + & + & + & ++ & +++ & +++ & ++ \\
\hline
\end{tabular}

Legends

$\begin{array}{llllll}\mathrm{ER} & =\text { Erythromycin } & \mathrm{CT} & =\text { Cotrimoxazole } & +++ & =\text { Highly sensitive } \\ \mathrm{AX} & =\text { Amoxicillin } & \mathrm{KA} & =\text { Kanamycin } & ++ & =\text { Moderately sensitive } \\ \mathrm{CP} & =\text { Cephalexin } & \mathrm{CI} & =\text { Ciprofloxacin } & + & =\text { Less sensitive } \\ \mathrm{CK} & =\text { Chloramphenicol } & \mathrm{NA} & =\text { Nalidixic acid } & - & =\text { Resistant }\end{array}$

Among the isolates $100 \%$ were highly sensitive to ciprofloxacin, $80 \%$ and $60 \%$ were to kanamycin and chloramphenicol respectively while $40 \%$ to cotrimoxazole and $20 \%$ to cephalexin. However $40 \%$ were moderately sensitive to nalidixic acid and cotrimoxazole while $20 \%$ were kanamycin, chloramphenicol and cephalexin. $60 \%, 25 \%$ and $20 \%$ were found to be less sensitive to cephalexin, amoxicillin and cotrimoxazole Fig. 5, Fig. 6). As regard effectivity of the antibiotics, $100 \%$ were highly resistant to erythromycin and $75 \%$ resistant to amoxicillin while $20 \%$ were resistant to nalidixic acid and chloramphenicol (Table 3 ).

Table 3. Antibiotic sensitivity pattern

\begin{tabular}{|ccccccccc|}
\hline Sensitivity pattern & \multicolumn{8}{c|}{ \% of isolated strain sensitive to various antibiotics } \\
\cline { 2 - 9 } & ER & AX & CP & CK & CT & KA & CI & NA \\
\hline Resistance & 100 & 75 & 0 & 20 & 0 & 0 & 0 & 20 \\
Less sensitive & 0 & 25 & 60 & 0 & 20 & 0 & 0 & 0 \\
Moderately sensitive & 0 & 0 & 20 & 20 & 40 & 20 & 0 & 40 \\
Highly sensitive & 0 & 0 & 20 & 60 & 40 & 80 & 100 & 40 \\
\hline
\end{tabular}


Isolation, identification and characterization of salmonella serovars

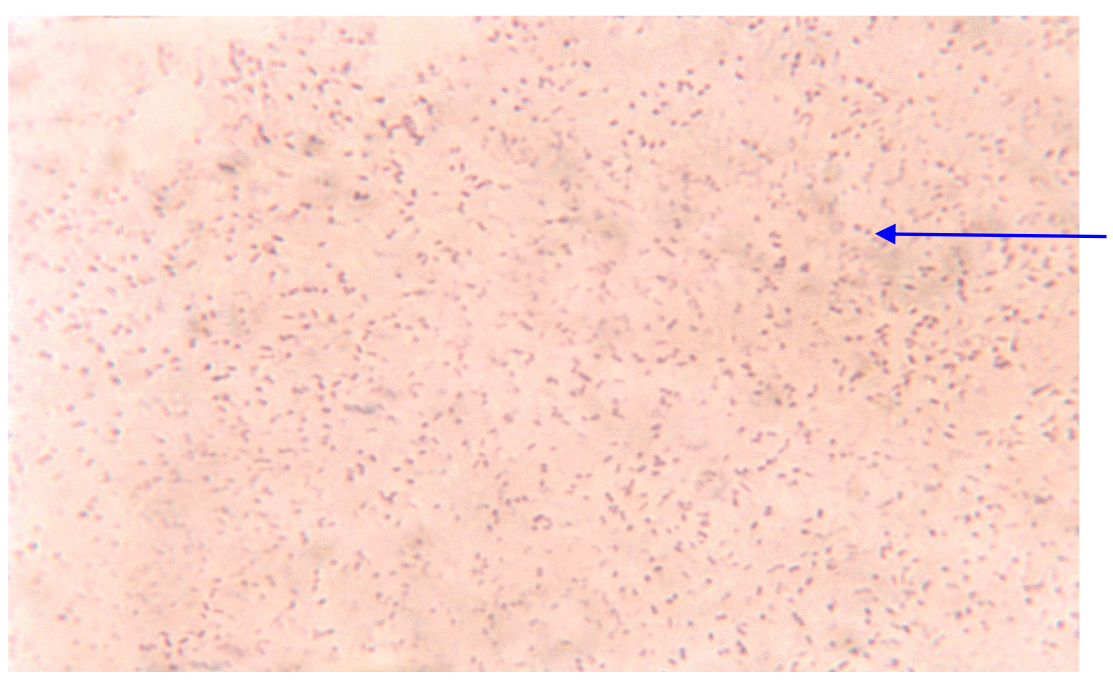

Pink colored Gram negative rods

Fig 1. Salmonella serovars showing Gram negative small rods arranged singly or pairs on Gram's staining (100X)

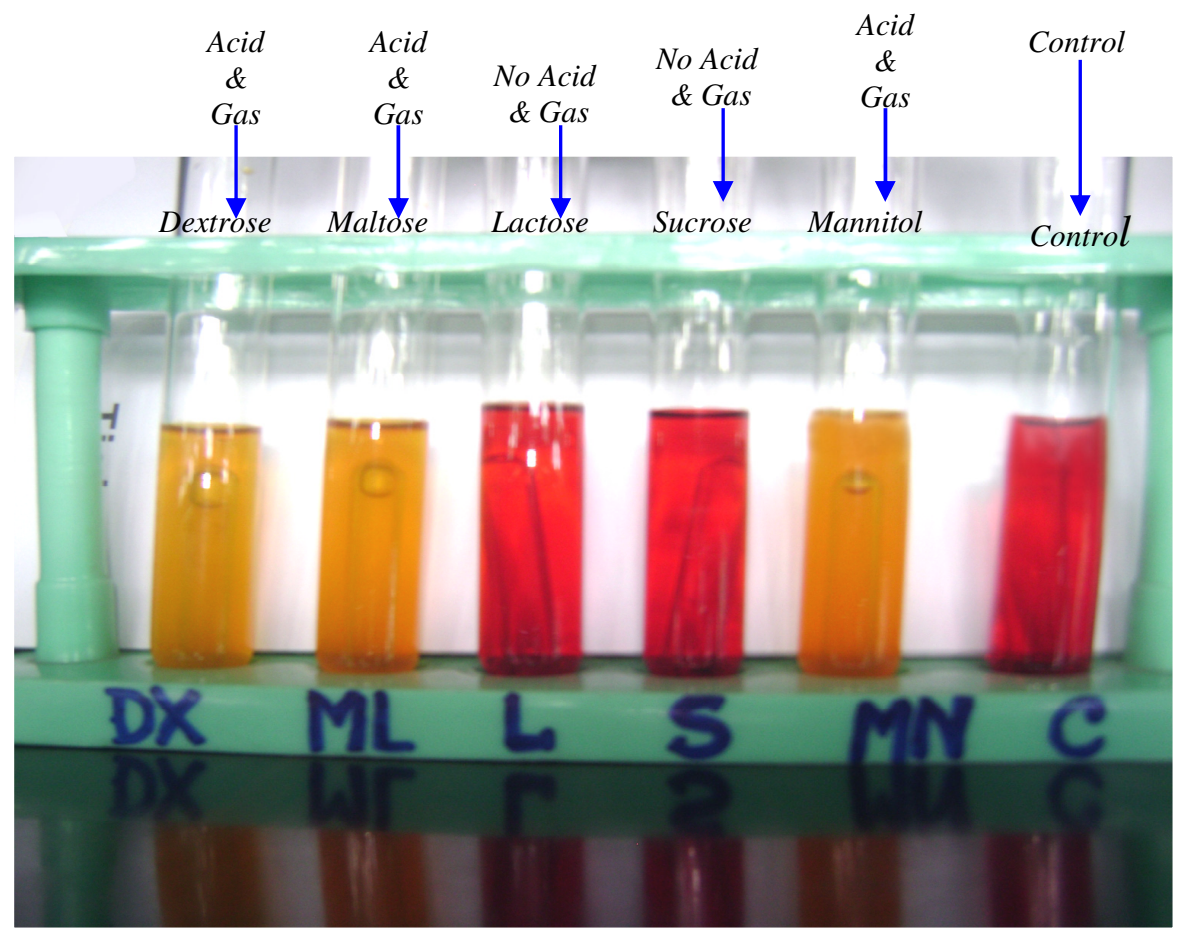

Fig 2. Sugar fermentation tests of Salmonella 


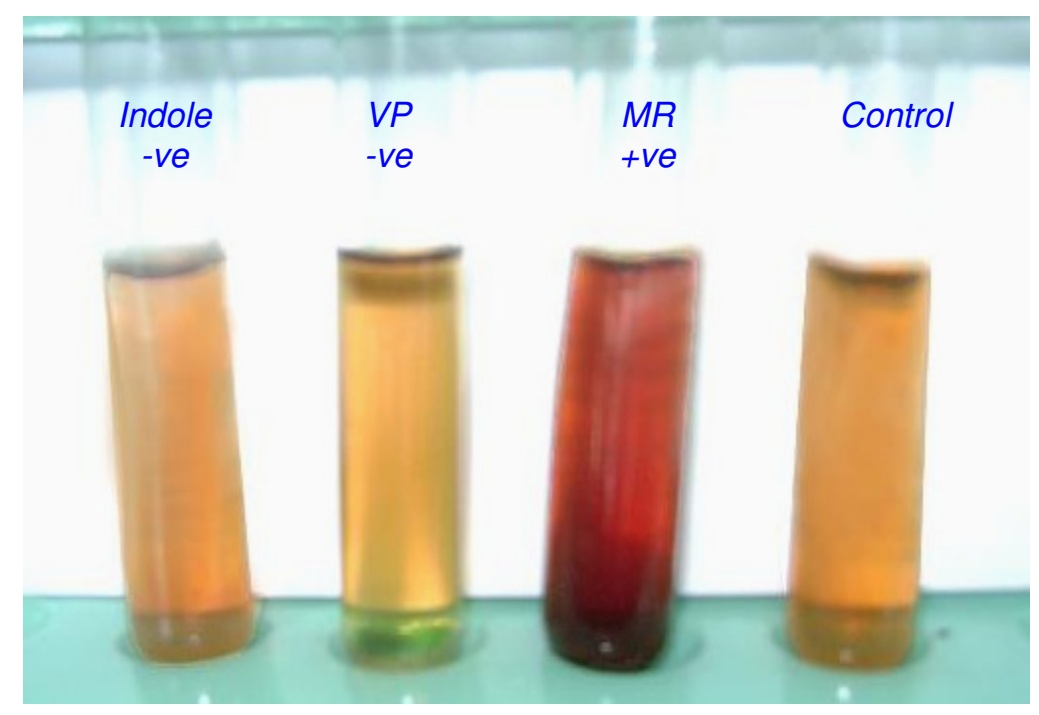

Fig 3. Indole, MR and VP tests

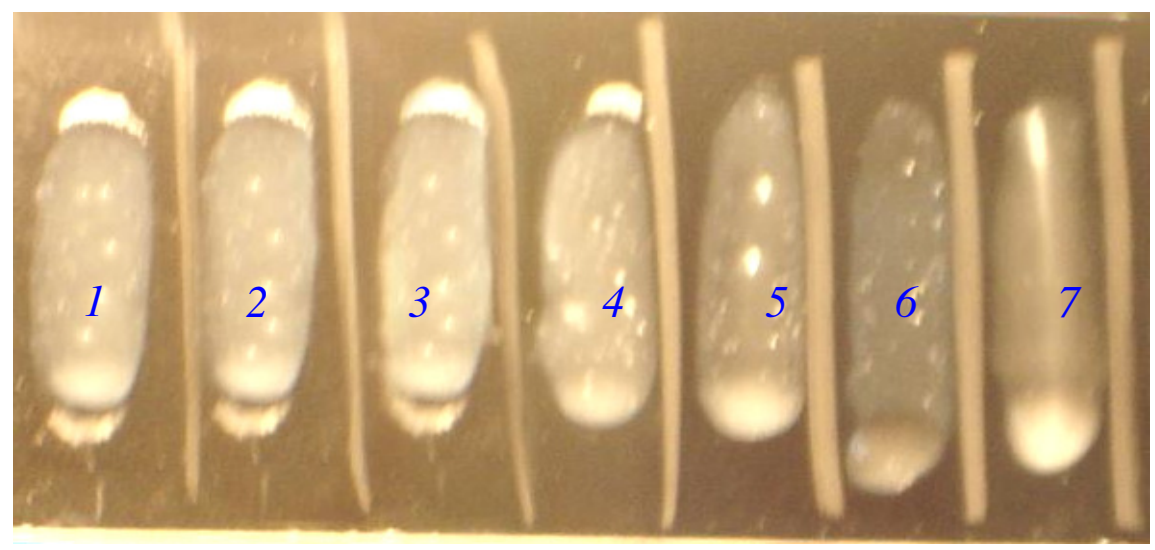

Fig 4. Serum plate agglutination test

1, 2, 3, 4, 5 = Agglutination, 6,7 = No Agglutination 
Isolation, identification and characterization of salmonella serovars

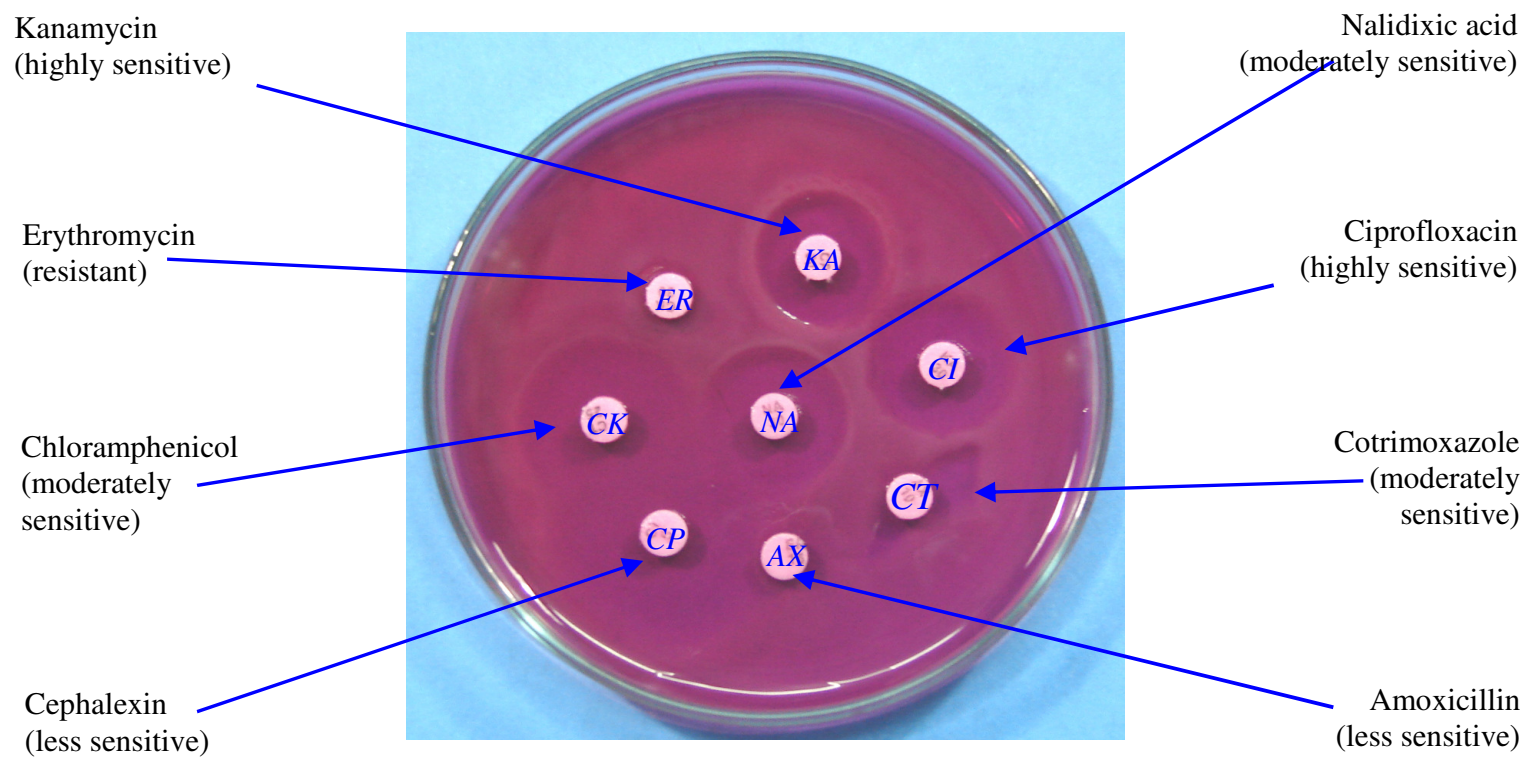

Fig 5. Antibiogram study of Salmonella serovars on BGA

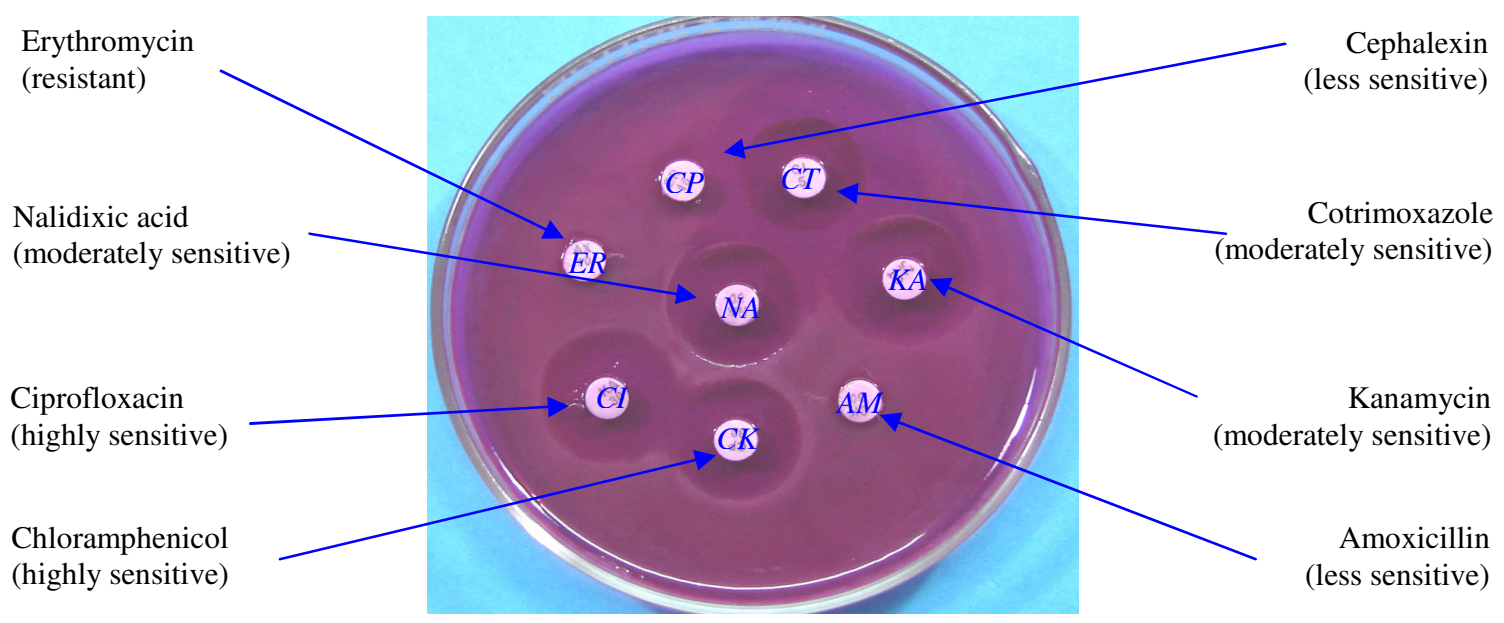

Fig 6. Antibiogram study of Salmonella serovars on BA 
In Gram's staining, the morphological characteristics of the isolated Salmonella exhibited Gram negative, small rod shaped, single or paired in arrangement under microscope which was supported by Sogard et al. (2007) and Gene (2002). In motility test, all isolates were found to be motile and was correlated with the results of Buxton and Fraser (1977). Salmonella isolates were able to ferment the five basic sugars by producing both acid and gas. However differentiation of Salmonella into species level was difficult based on their sugar fermentation pattern. All the isolates of this study fermented dextrose, maltose and mannitol and produced acid and gas but did not ferment sucrose and lactose which satisfied the statement of Buxton and Fraser (1977), Hossain (2002) and Han et al. (2011). Moreover, all the isolates were found to be negative to indole tests positive to MR and negative to VP. In the present study, the prevalence rate of Salmonella is $16 \%$. So, the results of this study are more or less in agree with the findings of the previous workers who also conducted research investigation on Salmonella from human stool sources. The slight differences among the prevalence percentages might be due to the species differentiation, hygienic, environmental and geographic variation and technical limitations of the laboratory of the study.

All culturally and biochemically positive Salmonella serovars showed agglutination with poly 'O' and in case of poly ' $\mathrm{H}$ ' all showed positive reaction. From the antibiotic sensitivity study, it was exhibited that all isolates were highly sensitive to ciprofloxacin, kanamycin and chloramphenicol; moderately sensitive to cotrimazole and nalidixic acid; and less sensitive to cephalixin. Theses findings are in support of other studies like Adesiym et al., (1988), Zhang et al., (1998) and FDA (2010). The antibacterial resistance observed here in the isolated Salmonellae might be due to routine indiscriminate use of those antibacterial agents in field condition in study areas and/or rapid chromosomal mutation and presence of specific plasmid DNA. This provided the guideline to the veterinarians and physicians to select appropriate antibiotics to reduce economic loss through selecting the sensitive antibiotics.

The development and use of antibiotic has been one of the most important steps towards controlling of infectious bacterial diseases in $21^{\text {st }}$ century. However, the subsequent appearance and spread of antibiotic resistance in pathogenic organisms have made many currently available antibiotics ineffective (Kam et al., 2007). To successfully fight the increasing number of drug resistant and multi drug resistance bacteria, extensive knowledge of the molecular mechanisms of acquiring antibiotic resistance and updated information is required. From the present study, it could be concluded that public health awareness should be developed to reduce the incidence of Salmonellosis among the people in order to avoid food borne illness. Proper treatment should be done with strict sanitary measures.

\section{ACKNOWLEDGEMENTS}

The authors are grateful to the Ministry of National Science and Information \& Communication Technology, Bangladesh for granting fellowship to do the research work.

\section{REFERENCES}

1. Adesiyun AA, Dasuki MO and Ibrahim GA (1988). Occurrence and antibiograms of Salmonellae isolated from slaughter sheep and goats in Zaria, Nigeria and Israel. Journal of Veterinary Medicine 44:248-255.

2. Bauser AW, Kirdy WMM, Sheris SC and Truck M (1966). Antibiotic susceptibility testing by a standardized single disk method. American Journal of Clinical Pathology 145: 225-230.

3. Buxton A and Fraser G (1977). Animal Microbiology. Blackwell Scientific Publications, Oxford. Vol.1:85110 .

4. Cheesbrough M (1985). Medical laboratory manual for tropical countries. Microbiology 2:400-480.

5. Cowan ST (1985). Cowan and Steel's Manual for Identification of Medical Bacteria. Cambridge University Press, Cambridge, London. $2^{\text {nd }}$ edition138-139.

6. Douglas W, Waltman R, Gast K and Mallinson ET (1998). Salmonellosis. A Laboratory Manual for the Isolation and Identification of Avian Pathogens. American Association of Avian Pathologists, Kenett Square. $4^{\text {th }}$ edn:4-14.

7. Dworkin MS, Shoemaker PC, Goldoft MJ and Kobayashi JM (2001). Reactive arthritis and Reiter's syndrome following an outbreak of gastroenteritis caused by Salmonella enteritidis. Clinical Infectious Diseases 33(7):10-14. 
8. FDA (2010). National Antimicrobial Resistance Monitoring System (NARMS) Enteric Bacteria Eexecutive Report. U.S. Department of Health and Human Services, Food and Drug Administration (FDA), Rockville, MD.

9. Gene O (2002). The isolation, identification and serotyping of Salmonella isolated from domestic poultry in Kars district. Kafkas Univarsikesi Veteriner Fakultesi Dergisi 8(1):23-30.

10. Han J, David JD, Aaron ML, Pravin K, Rajesh N, Rossina S and Steven LF (2011). Comparison of Salmonella enterica serovar Heidelberg isolates from human patients with those from animal and food sources. Journal of Clinical Microbiology 49:1130-1133.

11. Hossain KM (2002). Characterization of bacteria isolated from diarrhoeic calves. MS Thesis, Department of Microbiology and Hygiene, Bangladesh Agricultural University, Mymensingh.

12. Kam KM, Luey KY, Chiu AW, Law CP and Leung SF (2007). Molecular characterization of Salmonella enterica serotype typhi isolates by PFGE in Hong Kong, 2000-2004. Foodborne Pathology Diseases 4(1):41-49.

13. Khan AA, Melvin CD and Dagdag EB (2007). Identification and molecular characterization of Salmonella spp. from unpasteurized orange juices and identification of new serotype Salmonella strain S. enterica serovar. Food Microbiology 24(5):39-43.

14. Kumar Y, Sharma A, Sehgal R and Kumar S (2009). Distribution trends of Salmonella serovars in India (2001-2005). Trans. R. Society of Tropical Medical Hygiene 103(4):90-94.

15. Merchant IA and Packer RA (1967). Veterinary Bacteriology and Virology. 7th edn, The Iowa University Press, USA:286-306.

16. OIE (2000). Manual of Standards for Diagnostic Tests and Vaccines. Office International Des Epizooties.

17. Salam MA, Saha D, Khan WA and Bennish ML (2003). Non-Typhoidal Salmonella Infection and their Antimicrobial Resistance in Bangladesh. Interscience Conference on Antimicrobial Agents and Chemotherapy, Dhaka, Bangladesh.

18. Santiviago C A, Toro C S, Bucarey SA and Mora GC (2001). A chromosomal region surrounding the OmpD porin gene marks a genetic difference between Salmonella typhi and the majority of Salmonella serovars. Journal Medical Microbiology 147:1897-1907.

19. Sogard M, Norgaard M and Schonheyder HC (2007). First notification of positive blood cultures and the high accuracy of the gram stain report. Journal of Clinical Microbiology 45(4):1113-1117.

20. Steven LF, Rajesh N, Irene BH, Timothy JJ, Jing H and Steven CR (2011). Population dynamics of Salmonella enterica serotypes in commercial egg and poultry production. Applied Environmental Microbiology 77:4273-4279.

21. Tubaraie B, Sharma BK, Sharma PR, Sehgal NR and Ganguly NK (1994). Evaluation of Salmonella porins as a broad spectrum vaccine candidate. Microbiology and Immunology 38:553-559.

22. Zhang YX, Li JQ and Wang TG (1998). Isolation and identification of Salmonella typhimurium and composition of its pathogenicity with Salmonella enteritidis. Chainese Journal of Veterinary Science and Technology 28(9):26-27. 